\title{
Using audio-visual material to enhance laboratory practicals
}

\author{
Jennifer Schneider $^{1}$, Irene Munro ${ }^{2}, \&$ Siva Krishnan ${ }^{3}$ \\ Keywords: audio-visual, laboratory, independent learning
}

Framework

Laboratory practicals are an important part of science and health professional training. The literature suggests that active participation in the learning experience increases the student's ability to retain information (Weaver \& Jiang, 2005). Thus, the learning experience provided by laboratory practicals should give students the opportunity to expand, explore and experiment with ideas discussed in lectures (Guerrero, 2007), develop their hands-on skills and reinforce the theory delivered in lectures.

It is common practice for students to receive printed material for their practical laboratories prior to the scheduled laboratory session. The expectation is that the students will read this material and arrive at the laboratory well prepared and able to focus on learning. However, experience has shown that students often do not read through the supplied material and, if they do, may have difficulty translating words into required actions. As a result, practical laboratory sessions become more of a process of students focussing on step by step actions and not on the overall results or outcomes required. Spending time working in the laboratory is meaningless if students have merely gone through the motions and not considered their learning.

This generation of students, often referred to as "digital natives" (Prensky, 2001), has grown up with the internet and viewing videos on websites such as YouTube for both entertainment and learning how to do things. Therefore it seems logical to explore using this type of digital delivery as an alternative way for students to prepare for laboratory practicals and to assist their reflection on learning once the practical has been completed.

This article describes how teachers can use audio-visual resources to enhance laboratory practicals through:

- Providing an alternative and engaging method for students to prepare for practical laboratories

- Constructing a resource that can be easily referred to in the laboratory during practical laboratory session

- Developing resources which empower students to reflect upon their learning

\section{Making It Work}

While a decade ago, production of videos required expensive equipment and software and extensive training in using these, tools to produce videos quickly with minimal training are now readily available. Equipment such as the iPad, iPhone, similar tablet or smartphone devices or small portable video cameras can used to prepare videos. For laboratory practicals, each step of

\footnotetext{
${ }^{1}$ Associate Professor of Pharmacy and Clinical Pharmacology, The University of Newcastle, Jennifer.Schneider@newcastle.edu.au

2 Lecturer in Pharmacy and Clinical Pharmacology, The University of Newcastle, Irene.Munro@newcastle.edu.au

${ }^{3}$ Lecturer in Pharmacy and Clinical Pharmacology, The University of Newcastle, Siva.Krishnan@deakin.edu.au
} 
the practical and use of equipment can be captured using 2 people, one to perform the experiment and the other to operate the recording device. Each step can be recorded as an individual video file and these can be imported into software such as iMovie for easy editing. Using software such as iMovie on the iPad, the video can be easily edited and audio track added after video editing. Titles and jpg files containing pictures or words can be added at various points to emphasise key elements or points. The movie can then be uploaded onto a learning management system (LMS) for students to view before the class. Additionally, these videos can be made available on computers in the laboratory for students to revisit during the practical laboratory session or to watch again after the laboratory practical.

Audio-visual resources can also be used to reinforce important learning goals from the practical laboratory. Using software such as Captivate ${ }^{\circledR}$, Camtasia ${ }^{\circledR}$ or Articulate Pro ${ }^{\circledR}$, short presentations can be easily prepared. These can then be uploaded into the LMS as SCORM files which, when accessed in the LMS, open to start the presentation. Some software also allows the addition of quizzes during the presentation. Having these available after the practical laboratory allows students to reflect upon the practical exercises carried out in the laboratory.

Preparing audio-visuals does initially add to the teacher's workload. However, once these are prepared, they can be re-used for a number of years in many areas. The benefits of having audio-visual resources available are that, if students are unsure about certain steps in the practical, they can access the audio-visual on a computer or device rather than having to get the teacher in the laboratory to explain. This can streamline practicals from both the teacher and student perspective. When multiple different experiments are being performed at the same time by different students, without audio-visual resources, students are often waiting to ask the teacher for help or they just go ahead and in so doing make mistakes. At the end of the practical students may seek to clarify some of the learning goals or points of the practical. An audio-visual resource can be used as their first point of call and this may answer many of the questions that they would normally individually seek the teacher out to explain.

It is essential to make students aware of these resources well before the practical laboratory. One way of introducing students to this concept is to spend a few minutes at the end of a lecture demonstrating what is available and how to use these resources. Ensuring that computers available in the laboratory have appropriate software available to play the videos is also important. When recording the audio, it is important to ensure that it is sufficiently loud but not distorted, clear and concise. Using a LMS such as Blackboard, access and usage of these videos can also be monitored by the teacher. Teachers can determine which students are accessing the resources when they are being accessed and frequency of access.

The authors have used audio-visual resources for laboratory practicals for several cohorts of students enrolled in pharmaceutics practicals. Teachers have reported that, by having videos available in the laboratory, practical laboratory sessions have run more efficiently. Student feedback has been very positive with students saying it is a much more informative way to prepare for practicals. The students have also reported that the reflect/review resources are very useful and have helped them achieve greater learning.

\section{Future Implications}

In this paper, we have described an approach that can be used to enhance laboratory practicals. A possible barrier for teachers is the perception that it takes considerable time to learn to use technologies available for teaching. A simple way to demonstrate how easy it is to produce these 
resources could be to produce a short video demonstrating the steps involved (paralleling what is being done for student laboratories). The potential also exists for producing virtual laboratory practicals where students watch videos of experiments/procedures being performed and are able to record results from these procedures and analyse the data. This could be useful if a laboratory has limited access to expensive or specialised equipment.

Some practical laboratory sessions require students to generate a written report. Instead of a written report, the possibility exists for students to generate an audio-visual report which summarises what they did in the laboratory, what the results were and then discuss what their results mean and link the learning to core knowledge delivered in lectures. These audio-visual reports would also lend themselves to a peer review process.

\section{References}

Guerrero, C. (2007). Engaging our fears: student learning at the center of our practice. Horizon, 15(2), 99-106. doi: 10.1108/10748120710757334

Prensky, M. (2001). Digital Natives, Digital Immigrants Part 1. On the Horizon, 9(5), 1-6. doi: 10.1108/10748120110424816

Weaver, R. R., \& Jiang, Q. (2005). Classroom Organization and Participation: College Students' Perceptions. The Journal of Higher Education, 76(5), 570-601. doi: 10.1353/jhe.2005.0038 